\title{
On the Reduction of Stress Concentration Factor Around a Notch Using a Functionally Graded Layer
}

\author{
Sadek Gouasmi ${ }^{a, b}$, Abdelkader Meguenia, ${ }^{a, *}$, Aboubakar Seddik Bouchikhi ${ }^{a, b}$, \\ Kamel Zouggar ${ }^{a, b}$, Abderahmane Sahli ${ }^{a}$ \\ ${ }^{a}$ Faculty of Technology, University of Sidi Bel Abbès, Sidi Bel Abbes, BP 89, \\ Cité Ben M'hidi, 22000, Algeria \\ ${ }^{b}$ Laboratory of Structures and Solids Mechanics - LMSS, Faculty of Technology, University of Sidi Bel \\ Abbès, Sidi Bel Abbes, BP 89, Cité Ben M’hidi, 22000, Algeria
}

Received: May 5, 2015; Revised: August 30, 2015

\begin{abstract}
The aim of this paper is to study the effect of functionally graded material (FGM) layer around a notch in a plate in three dimensions. Using exponential law of variation of Young's modulus and a coefficient of Poisson constant, the stress concentration factor (SCF) depends on the gradation direction of the constituent materials. The finite element method is used to study the performance of FGM layer around a notch in a ceramic plate under in tensile load. A parametric study is performed for several geometric and mechanical parameters such that width of the FGM layer and the ratio of FGM layer components. The effect of notch radius is also studied.
\end{abstract}

Keywords: FGM layer, notch, plate, exponential law, SCF, finite element method

\section{Introduction}

Since the beginning of the century, the use of composite materials in the form of plate and beam has expanded considerably to this day whether in the automotive, construction, and more recently in aeronautic. The composite materials have significant advantages over traditional materials. In conventional multilayer structures, layered composite materials are used to improve the performance (mechanical, thermal, acoustic...) of the structure (plate). The disadvantage of this type is to create stress concentrations at the interfaces due to the change of mechanical and thermal properties. In the late $80 \mathrm{~s}$, a team of Japanese researchers has proposed to overcome these difficulties by developing new materials known as functionally graded materials (FGM). Functionally graded materials are composites in which the material properties vary continuously as a known function of the spatial position; these materials are usually associated with particulate composite where the volume fraction of particles varies in one or several directions. The initial development of FGMs is designed to serve as a thermal barrier ${ }^{1}$. Today, there have been more and more numerous modern engineering applications of FGM, like the spacecraft, rocking engine casings and packaging materials in the microelectronics industry, biomaterials (dental implants) and others ${ }^{2,3}$.

The metallurgical field has also been the subject of recent research work dealing with the behavior of functionally graded steels ${ }^{4,5}$. The effect of a band in FGM around a hole in a homogeneous plate was analyzed for the reduction of the SCF under biaxial loading ${ }^{6}$. Many researchers were interested in calculating the stress concentration factor (SCF) in FGM plates for two types of holes (circular, elliptical) ${ }^{7-12}$. In the

*e-mail: a_megueni@yahoo.fr present work, we used the finite element method to calculate the stress concentration factor at the edge of a notch in a homogeneous ceramic plate and TiB FGM plate for different combinations ceramic-metal. The calculation of FGM's stress concentration $\mathrm{SC}$ involves three directions $(\mathrm{x}, \mathrm{y})$ and the direction of the radius of the notch. To reduce the SCF, we used a FGM layer around a notch in a homogeneous ceramic under uniaxial load. The graded finite elements are implemented in the FE software Abaqus ${ }^{13}$ to verify the UMAT used subroutine (Appendix).

\section{Problem Formulation}

A Functionally graded material plate with a semicircular lateral notch is subjected to uniaxial tensile load equal to $\sigma_{0}=100 \mathrm{MPa}$ (Figure 1). Geometric characteristics of the plate are:

Width $\mathrm{W}=20 \mathrm{~mm}$; height $\mathrm{H}=2 \mathrm{~W}$ and thickness denoted $\mathrm{t}=2 \mathrm{~mm}$. The lateral notch has a radius $\mathrm{r}=\mathrm{a}$.

The origin of the coordinates coincides with the center of the notch lateral. For reasons of symmetry of loading and geometry, half of the plate has been studied (Figure 1). The boundary conditions of the model were imposed by constraining the y-displacements $(\mathrm{U} 2=0)$ at $\mathrm{y}=0$ and rotations around the axes ox and $\mathrm{oz}(\mathrm{UR} 3=0$ and $\mathrm{UR} 2=0)$ at $y=0$ in the Oxz plane of symmetry of the full model. The properties of the different constituents of the FGM (metal, ceramic) used are indicated in Table 1.

The Figure 2 shows the law graph for different combinations of metal-ceramic. The FGM material is expressed by the following exponential law:

$\mathrm{E}(\xi)=\mathrm{E}_{2} \mathrm{e}^{\beta \xi}$ 


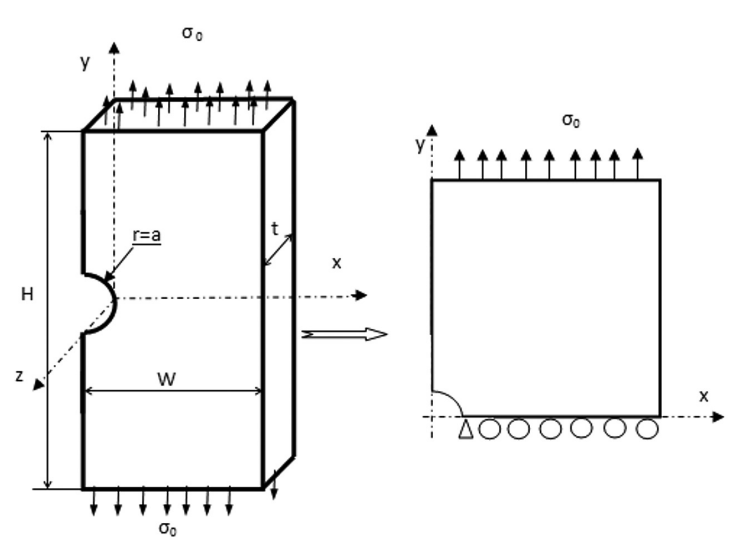

Figure 1. Geometric model of the plate with a lateral notch circular, (a) the entire plate, (b) half of the plate.

Table 1. Material properties of the FGM used in calculations.

\begin{tabular}{ccc}
\hline Nature & Young's modulus (GPa) & Poisson ratio \\
\hline $\mathrm{Al}$ & 72 & 0.3 \\
$\mathrm{Ti}$ & 110 & 0.3 \\
$\mathrm{Cu}$ & 124 & 0.3 \\
$\mathrm{Ni}$ & 215 & 0.3 \\
$\mathrm{TiB}$ & 375 & 0.3 \\
\hline
\end{tabular}

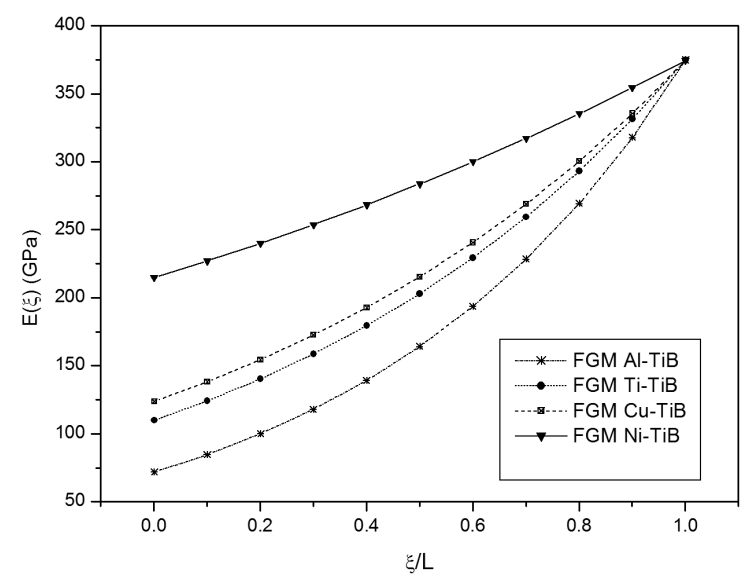

Figure 2. Exponential variation of Young's modulus for different combinations of the constituents.
With:

$\beta=\frac{1}{L} \log \left(\frac{E_{I}}{E_{2}}\right)$

Where $\mathrm{E}_{2}=\mathrm{E}(0)$ is the Young's modulus of the metal and $\mathrm{E}_{1}$ the Young's modulus of ceramic.

Different functionally graded material configurations can be obtained by varying the gradation direction of the constituent materials as:

$$
\begin{aligned}
& \xi=\mathrm{x} \text { and } \mathrm{L}=\mathrm{W} \text { for } \mathrm{x}-\mathrm{FGM} \text { (Figure } 3 \mathrm{a}) . \\
& \xi=\mathrm{y} \text { and } \mathrm{L}=\mathrm{W} \text { for } \mathrm{y}-\mathrm{FGM} \text { (Figure } 3 \mathrm{~b} \text { ). } \\
& \xi=\sqrt{x^{2}+y^{2}} \text { and } \mathrm{L}=\mathrm{W} \sqrt{2} \text { for r-FGM (Figure } 3 \mathrm{c} \text { ). }
\end{aligned}
$$

\section{Finite Element Modeling}

For modeling the Young's modulus in a desired direction, the subroutine UMAT Abaqus was used ${ }^{14}$. The routine is written in FORTRAN language and runs in parallel with the Abaqus solver. It allows us to establish an algorithm to calculate the variables used by the solver Abaqus. The routine was coded so that the material stiffness matrices are established with appropriate material properties, namely, the Young's modulus. In this study, the Poisson's ratio is assumed constant, since it has been shown that variations in the Poisson ratio are much less important than the Young's modulus ${ }^{15}$. Calculating the stiffness matrix requires the use of the Gaussian quadrature ${ }^{16}$.

A half symmetric model of a $20 \times 20 \mathrm{~mm}^{2}$ plate and a thickness $t$ with $2 \mathrm{~mm}$ radius center notch was used for verification as shown in Figure 4. The mesh was refined around the center notch and was graded in the direction moving away from the notch toward the outer boundaries. The initial mesh consisted of 13810 C3D20R quadratic brick, full integration stress elements with 276200 nodes. The base Young's modulus is TiB with $\mathrm{E}_{1}=375 \mathrm{GPa}$ and $\mathrm{E}_{2}$ is the metal Young's modulus. The Poisson's ratio was held constant equal to 0.3 .

\section{Results and Analyses}

The finite element method has allowed us to calculate the normalized stress concentration of a notched plate noted $\mathrm{Kt}$ for different directions of FGM and a constant normalized thickness $(\mathrm{t} / \mathrm{W}=0.1)$. The stress concentration allows increasing

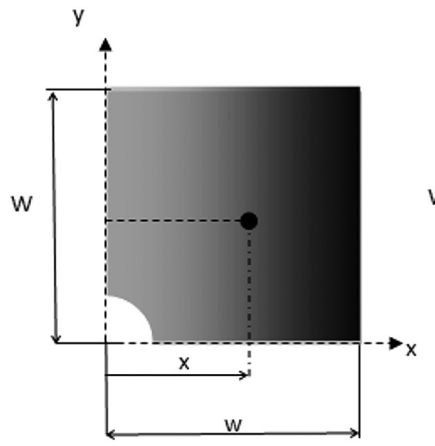

a) $x-F G M$

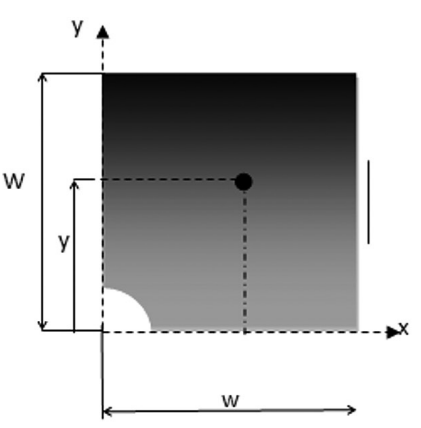

b) $\mathrm{y}-\mathrm{FGM}$

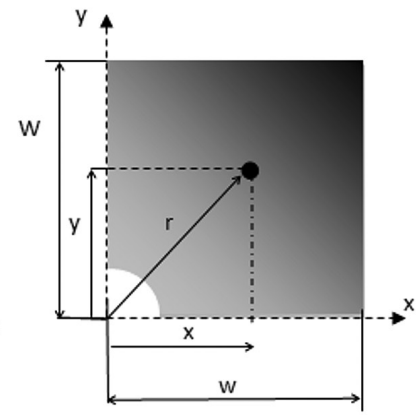

c) r-FGM

Figure 3. Direction of the FGM Young's modulus FGM (a) x-FGM variation, (b) y-FGM variation, (c) r-FGM variation. 


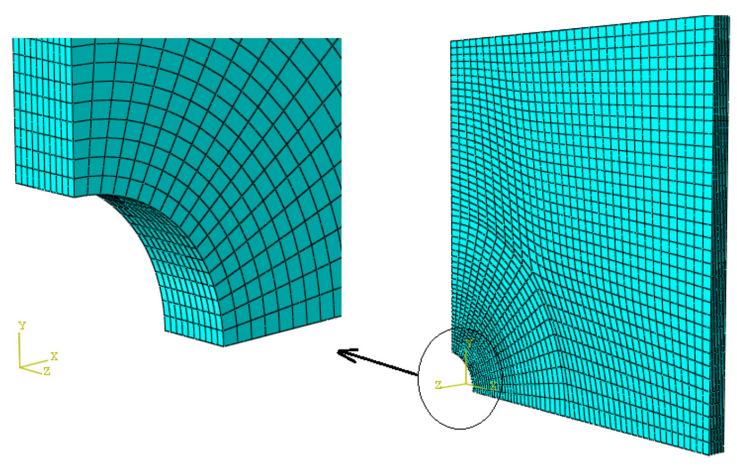

Figure 4. Model verification mesh with 13810 C3D20R elements.

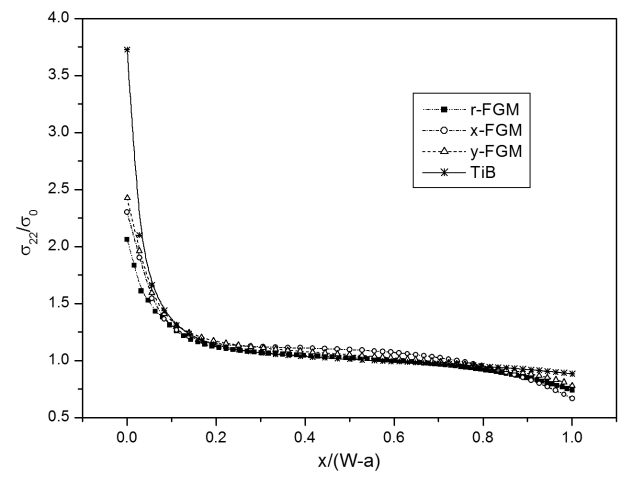

Figure 5. Variation of normalized normal stresses vs normalized $\mathrm{x}$ for different gradation direction of Ti-TiB FGM.

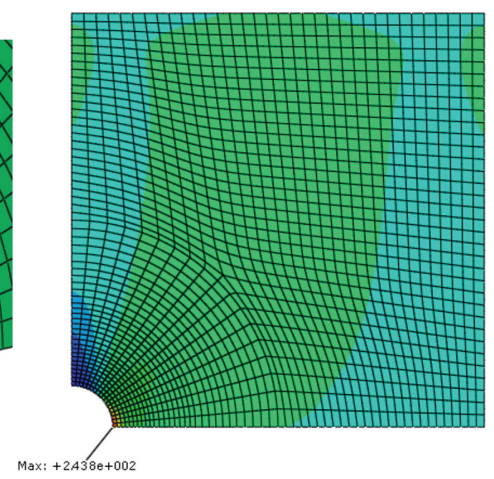

(a)

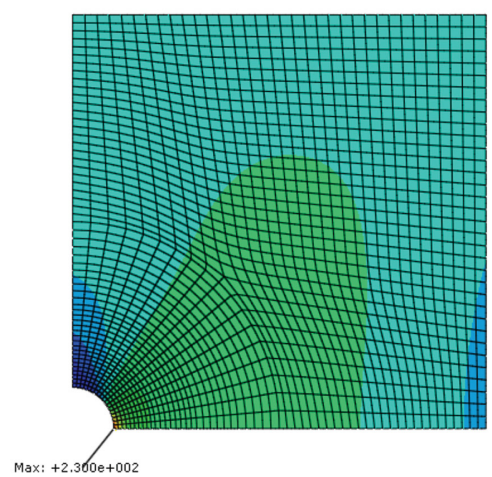

(b)

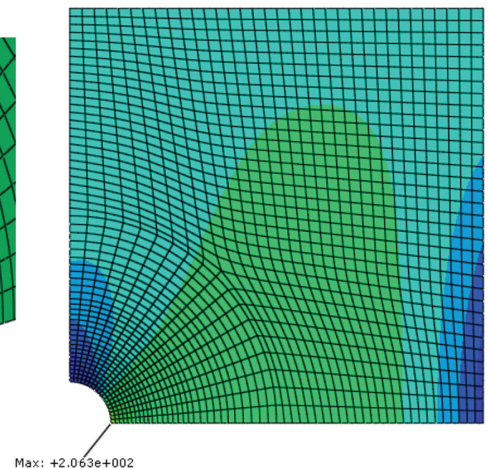

(c)

Figure 6. Strain max contours for different gradation direction distribution of FGM (a) x-FGM variation, (b) y-FGM variation, (c) r-FGM variation. 
the stress at the notch root. The factor $\mathrm{Kt}$ is defined by the ratio of the maximum stress to the applied stress $\sigma_{0}$ :

$$
K_{t}=\frac{\sigma_{\max }}{\sigma_{0}}
$$

In the case of a homogeneous and isotropic plate, $\mathrm{Kt}$ is called stress concentration factor. The Figure 5 shows the normalized distribution of $\sigma_{22}$ stress versus $\mathrm{x}$ from the edge of the notch for the tree direction of FGM and the normalized distribution of $\sigma_{22}$ stress of ceramic.

In our case, the stress $\sigma_{\max }$ represents the normal stress along the $\mathrm{y}$ axis at the edge of the notch at $\mathrm{y}=0$ and noted $\sigma_{22 \max }$. The value of $\sigma_{22 \max }$ is taken in the middle of the thickness where it is maximum (Figure 6). The maximum values are naturally obtained at notch edge (Figure 6). We deduce that the direction of FGM along $r$ gives the minimum value. We note that FGM distribution management for the rest of the study. The gain of normalized stress concentration (Kt) of an r-FGM plate at the edge of the notch is $44 \%$ compared to a homogeneous ceramic plate.

The field of deformation shape of the plate is similar to the graduated FGM modulus for the three directions (Figure 7). The maximum deformation is lower in the case of r-FGM.
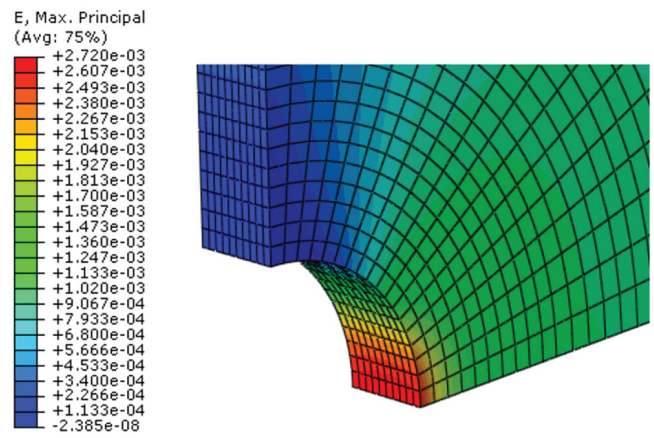

(a)
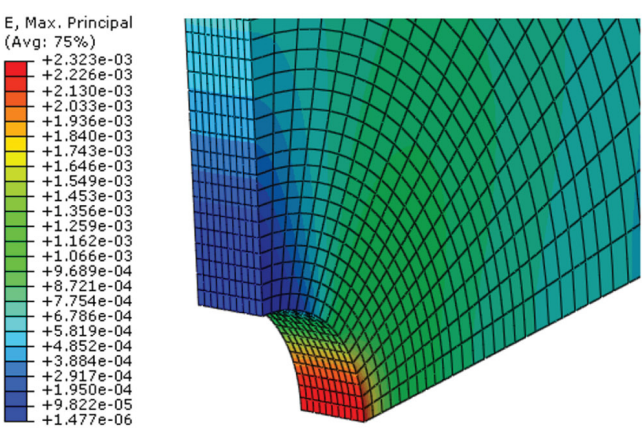

(b)
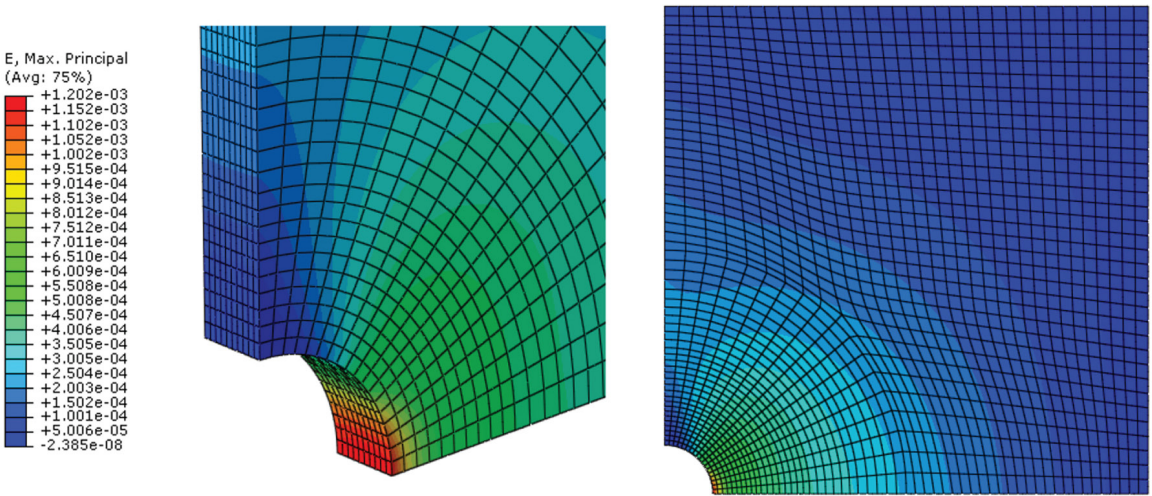

(c)
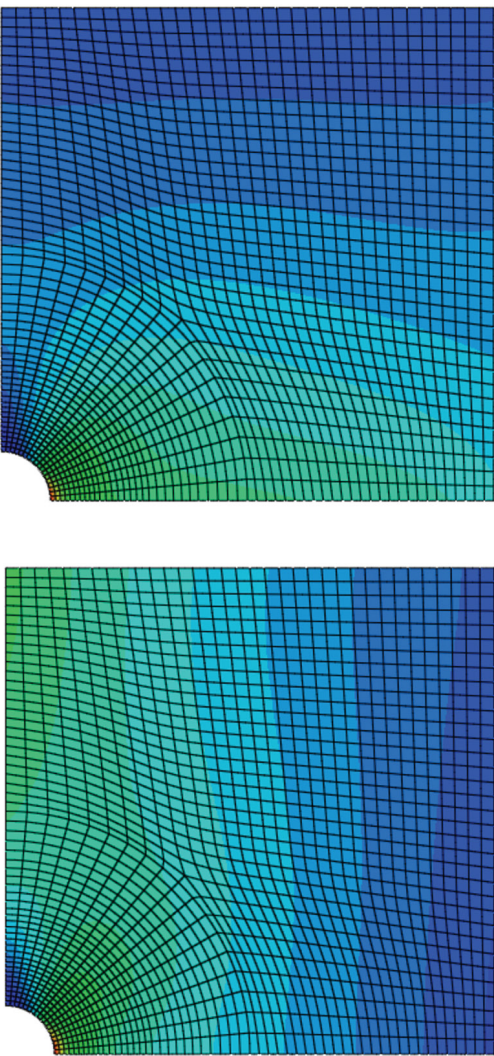

Figure 7. Stresses contour for different gradation direction distribution of FGM (a) x-FGM variation, (b) y-FGM variation, (c) r-FGM variation. 


\subsection{Parametric study}

The profile of the stress distribution $\sigma_{22}$ normalized along the $\mathrm{x}$-axis is the same for the various combinations of metal-ceramic. The decrease of the stress concentration factor

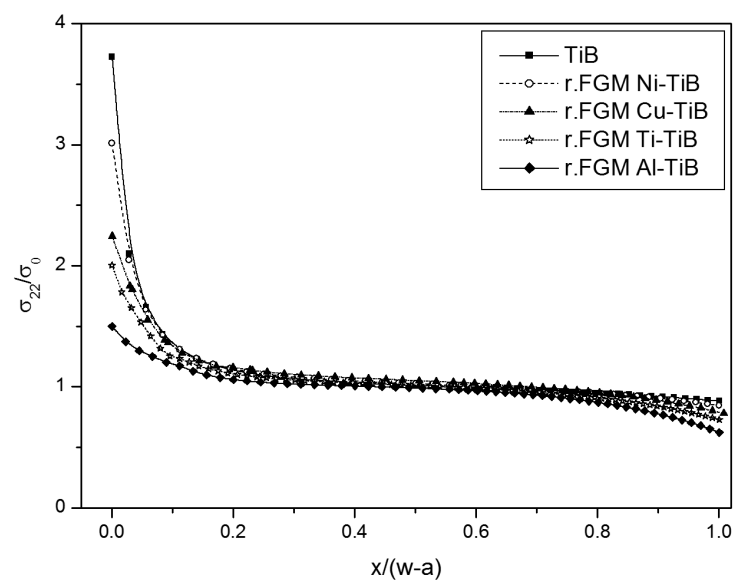

Figure 8. Variation of normalized normal stresses vs normalized $x$ for different combinations of the FGM.

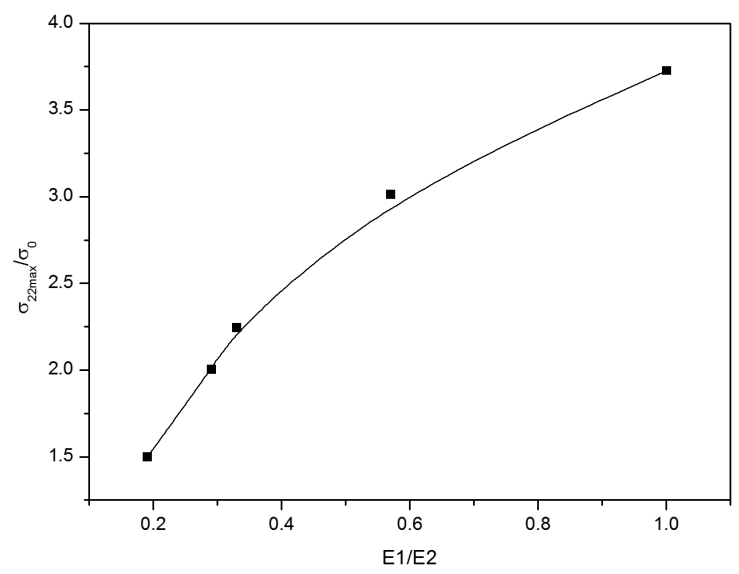

Figure 9. Variation of the stress concentration factor Kt based on the normalized $\mathrm{x}$ for different ratios $\mathrm{E} 1$ / E2.

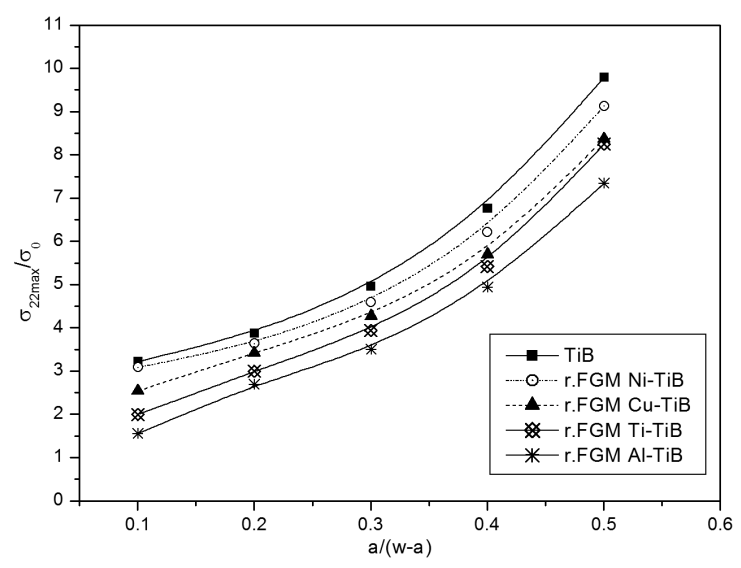

Figure 10. Variation of stress concentration factor as a function of normalized radius of notch for different ratios E1 / E2. at the edge of the notch is proportional to the decrease in the $\mathrm{E}_{1} / \mathrm{E}_{2}$ report. For a normalized depth graduation of FGM between 0.4 and 0.7 , the normalized stress tend towards the value 1 , for a standardized depth graduation of FGM superior to 0.7 , the stresses decrease slightly (Figure 8 ). The greatest reduction of the stress concentration factor at the edge of the notch is obtained for the combination AL-TiB and is about $60 \%$ compared to the TiB ceramics (Figure 9).

Figure 10 shows the evolution of $\mathrm{K}_{t}$ as a function of the normalized notch radius for different combinations of the FGM. $\mathrm{K}$ increases with increasing radius of the notch for all combinations. $\mathrm{E}_{2}$ is the Young modulus of ceramic.

\subsection{Effect of the FGM layer}

To analyze the effect of the FGM layer, a ceramic plate in TiB contains a r-FGM layer in Ti-TiB with a width $h$ $(\mathrm{h}=\mathrm{b}-\mathrm{a})$ around a circular lateral notch of radius a (Figure 11).

We observe that an increase of the width $h$ corresponds to a decrease of the Kt value at the rim of the notch and, at the same time, we have an increase of the interface $\mathrm{Kt}$ (Figure 12). The Kt at the rim of the notch is noted $\mathrm{Ka}$ and the other $\mathrm{Kb}$. The use of a standard FGM layer Ti-TiB

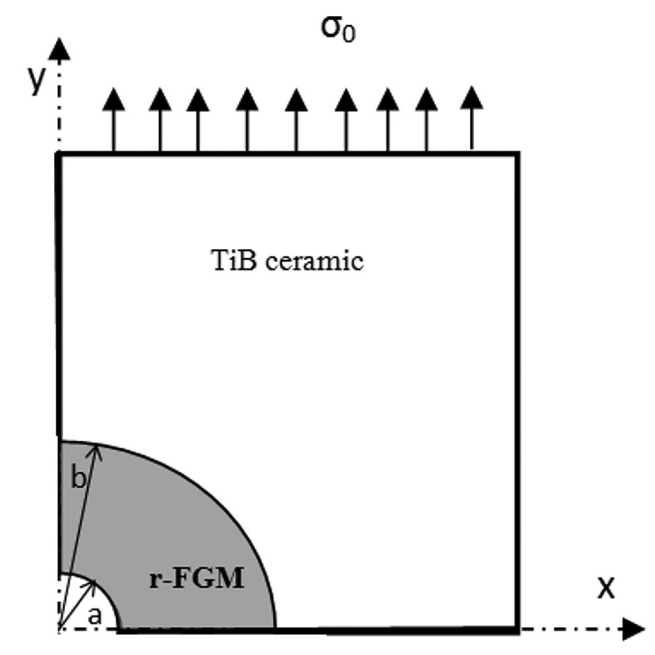

Figure 11. A geometric model FGM layer in a ceramic plate.

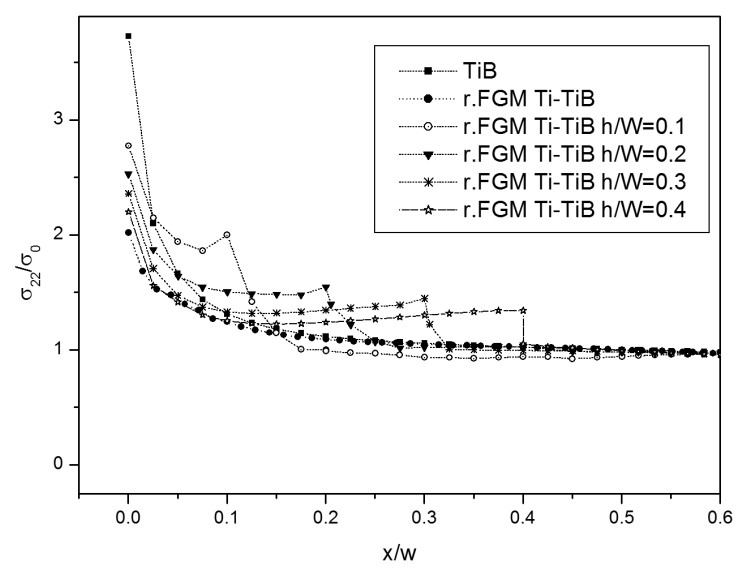

Figure 12. Variation of normalized normal stresses vs normalized $\mathrm{x}$ for different normalized witdh of FGM layer. 


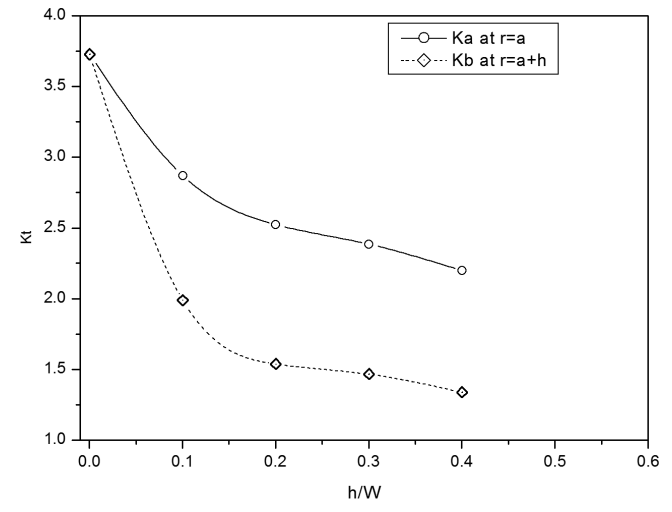

Figure 13. Variation of $\mathrm{Ka}$ and $\mathrm{Kb}$ depending on the normalized width of FGM layer.

Table 2. The gain of SCF Ka and $\mathrm{Kb}$ for different normalized width of layer.

\begin{tabular}{|c|c|c|}
\hline \multirow{2}{*}{$\begin{array}{c}\text { Normalized } \\
\mathbf{h} / \mathbf{W}\end{array}$} & \multicolumn{2}{|c|}{ Gain (\%) } \\
\hline & $\Delta \mathrm{Ka} / \mathrm{Kt}$ & $\Delta \mathrm{Kb} / \mathrm{Kt}$ \\
\hline 0.1 & 25.54 & 46.50 \\
\hline 0.2 & 32.26 & 58.60 \\
\hline 0.3 & 36.83 & 60.75 \\
\hline 0.4 & 41 & 64 \\
\hline
\end{tabular}

\section{References}

1. Hirano T, Teraki J and Yamada T. On the design of functionally gradient materials. In: Yamanouchi M, Koizumi M, Harai T and Shiota I, editors. Proceedings 1st International Symposium on Functionally Gradient Materials; 1990; Sendai. Sendai: Functionally Gradient Materials Forum; 1990. p. 5-10.

2. Watari F, Yokoyama A, Saso F, Uo M, Ohkawa S and Kawasaki T. EPMA elemental mapping of functionally graded dental implant in biocompatibility test. In: Shiota I and Miyamoto Y, editors. Proceedings 4th International Symposium on Functionally Graded Materials; 1996; Tsukuba. Heidelberg: Elsevier; 1996. p. 749-754.

3. Oonishi H, Noda T, Ito S, Kohda A, Yamamoto H and Tsuji E. Effect of hydroxyapatite coating on bone growth into porous Titanium alloy implants under loaded conditions. Journal of Applied Biomaterials. 1994; 5(1):23-27. http://dx.doi.org/10.1002/ jab.770050105.

4. Abolghasemzadeh M, Pour HSS, Berto F and Alizadeh Y. Modeling of flow stress of bainitic and martensitic functionally graded steels under hot compression. Materials Science and Engineering A. 2012; 534:329-338. http://dx.doi.org/10.1016/j. msea.2011.11.077.

5. Jam JE, Abolghasemzadeh M, Salavati $\mathrm{H}$ and Alizadeh Y. The effect of notch tip position on the charpy impact energy for bainitic and martensitic functionally graded steels. Strength of Materials. 2014; 46(5):700-716. http://dx.doi.org/10.1007/ s11223-014-9604-0.

6. Sburlati R, Atashipour SR and Atashipour SA. Reduction of the stress concentration factor in a homogeneous panel with hole by using a functionally graded layer. Composites. Part B, Engineering. 2014; 61:99-109. http://dx.doi.org/10.1016/j. compositesb.2014.01.036.

7. Sburlati R. Stress concentration factor due to a functionally graded ring around a hole in an isotropic plate. International $(\mathrm{h} / \mathrm{W}=0.4)$ leads to a significant decrease of Ka with a gain of $41 \%$ and a gain of $64 \%$ for the $\mathrm{Kb}$ with respect to a ceramic plate. We observe that the value of $\mathrm{Kt}=2.02$ of a complete r-FGM is close to that of $\mathrm{Ka}(\mathrm{Ka}=2.2)$ of a plate with the same size of the layer.

Figure 13 shows the evolution of $\mathrm{Ka}$ and $\mathrm{Kb}$ depending on the width of the layer. The values of $\mathrm{Ka}$ and $\mathrm{Kb}$ tend respectively to 2.2 and 1.32 . The gains of $\mathrm{Ka}$ and $\mathrm{Kb}$ are summarized in Table 2 which are respectively $41 \%$ and $64 \%$.

\section{Conclusion}

The use of FG-layer is another way to increase the performance of the notched structures.

The use of a r-FGM or r-FGM layer in a ceramic notched plate allowed to draw the following conclusions:

- The variation of the FGM properties in the direction of notch radius (r-FGM) offers the best favorable stress concentration factor compared to other directions.

- The smallest ratio $\mathrm{E}_{1} / \mathrm{E}_{2}$ is one that gives the best guarantee.

- The use of FGM layer around the notch of a standardized width less than 0.5 gives the best possible performance.

Journal of Solids and Structures. 2013; 50(22-23):3649-3658. http://dx.doi.org/10.1016/j.ijsolstr.2013.07.007.

8. Makwana AB, Panchal KC and Gandhi AH. Stress analysis of functionally graded material plate with cut-out. International Journal of Advanced Mechanical Engineering. 2014; 4(5):495500 .

9. Enab TA. Stress concentration analysis in functionally graded plates with elliptic holes under biaxial loadings. Ain Shams Engineering Journal. 2014; 5(3):839-850. http://dx.doi. org/10.1016/j.asej.2014.03.002.

10. Kubair DV and Bhanu-Chandar B. Stress concentration factor due to a circular hole in functionally graded panels under uniaxial tension. International Journal of Mechanical Sciences. 2008; 50(4):732-742. http://dx.doi.org/10.1016/j.ijmecsci.2007.11.009.

11. Yang QQ, Gao CF and Chen WT. Stress concentration in a finite functionally graded material plate, Physics. Mechanics \& Astronomy. 2012; 55(7):1263-1271. http://dx.doi.org/10.1007/ s11433-012-4774-x.

12. Saini PK and Kushwaha M. Stress variation around a circular hole in functionally graded plate under bending. International Journal of Mechanical, Aerospace, Industrial and Mechatronics Engineering. 2014; 8(3):536-540.

13. Dassault Systèmes. Abaqus software manual: version 6.10 . Providence: Dassault Systèmes Simulia Corp; 2011.

14. Buttlar WG, Paulino GH and Song SH. Application of graded finite elements for asphalt pavements. Journal of Engineering Mechanics. 2006; 132(3):240-249. http://dx.doi.org/10.1061/ (ASCE)0733-9399(2006)132:3(240).

15. Sadd MH. Elasticity, theory, applications \& numerics. Boston: Elsevier Academic Press; 2009.

16. Manneth V. Numerical studies on stress concentration in functionally graded materials. [Dissertation]. Kingston: University of Rhode Island; 2009. 
Appendix. User subroutine UMAT x-FGM.

c User subroutine for implementation of a continuous variation

c of the material elastic properties between integration points.

$\mathrm{c}$

c ABAQUS 6.11 - user subroutine UMAT for functionally graded materials

c where $\mathrm{E}(\mathrm{X})$

SUBROUTINE UMAT (STRESS, STATEV, DDSDDE, SSE, SPD, SCD,

1 RPL, DDSDDT, DRPLDE, DRPLDT,

2 STRAN, DSTRAN, TIME, DTIME, TEMP, DTEMP, PREDEF, DPRED, CMNAME,

3 NDI, NSHR, NTENS, NSTATV, PROPS, NPROPS, COORDS, DROT, PNEWDT,

$\mathrm{C}$

4 CELENT, DFGRD0, DFGRD1, NOEL, NPT, LAYER, KSPT, KSTEP, INC)

$\mathrm{C}$

INCLUDE 'ABA_PARAM.INC'

CHARACTER *80 CMNAME

DIMENSION STRESS (NTENS), STATEV (NSTATV),

1 DDSDDE (NTENS, NTENS), DDSDDT (NTENS), DRPLDE (NTENS),

2 STRAN (NTENS), DSTRAN (NTENS),TIME(2),PREDEF(1), DPRED(1),

3 PROPS(NPROPS),COORDS(3),DROT(3,3),DFGRD0(3,3),DFGRD1(3,3)

c

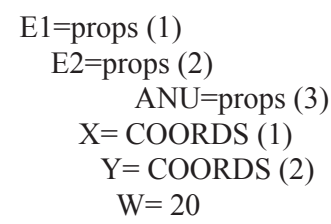

c

c W is Width of plate and a is radus of lateral notch

c Determine L

$$
\mathrm{L}=\mathrm{W}
$$

Determine material properties based on global coordinates of gauss points.

c COORDS(1) is X-coordinates of gauss points.

c PROPS is defined by users.

c The function can be also defined by users.

$$
\mathrm{E}=\mathrm{E} 2 * \exp (\log (\mathrm{E} 1 / \mathrm{E} 2) / \mathrm{L}) * \mathrm{X}
$$

c

$\mathrm{amu}=\mathrm{E} / 2.0 \mathrm{~d} 0 /(1.0 \mathrm{~d} 0+\mathrm{ANU})$

alambda $=\mathrm{E}^{*} \mathrm{ANU} /(1.0 \mathrm{~d} 0+\mathrm{ANU}) /(1.0 \mathrm{~d} 0-2.0 \mathrm{~d} 0 * \mathrm{ANU})$

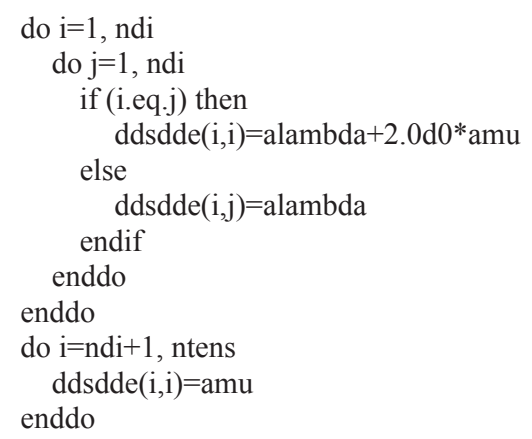

c

$\mathrm{c}$

STRESSES AND STRAINS AT END OF TIME STEP

c

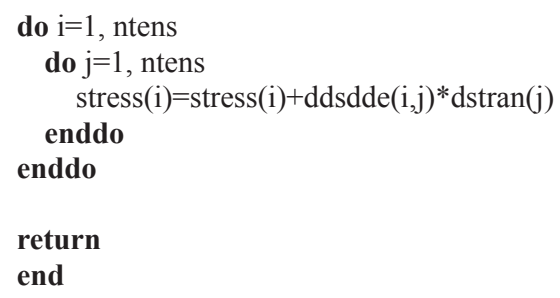

